ARTIGO

\title{
Juvenilização da EJA e as implicações no processo de escolarização
}

Alcides Alves de Souza Filho ${ }^{a}$ Atenuza Pires Cassol ${ }^{b}$

Antonio Amorim ${ }^{c}$

\section{Resumo}

O estudo analisa a juvenilização na Educação de Jovens e Adultos (EJA), destacando as causas desse processo e as implicações na escolarização. Objetiva refletir sobre os motivos que determinaram a inserção dos jovens na EJA, especificando as causas e os impactos vivenciados. A abordagem da pesquisa é qualitativa, ancorada, estrategicamente, na pesquisa de campo. A coleta de dados foi lograda com o uso do questionário semiestruturado, aplicado junto aos sujeitos da investigação: 27 professores e 37 alunos de escolas públicas de Barreiras e de Salvador, na Bahia. Os resultados apontaram a interferência da atividade laboral dos estudantes no processo de escolarização; a luta pela garantia do acesso/ permanência na escola; a prática pedagógica e a gestão escolar como promotoras da inclusão com diálogo, da qualidade de ensino e de equidade.

Palavras-chave: EJA. Juvenilização. Ensino de qualidade. Escolarização.

\section{Introdução}

No histórico da Educação de Jovens e Adultos (EJA), registramos a concepção inicial voltada para atender a uma parcela da sociedade, em sua maioria jovens e adultos trabalhadores e idosos, com o propósito de proporcionar a esses sujeitos, que não estudaram na idade adequada, uma ação reparadora de direito e uma Educação equitativa, qualificadora e de atualização de aprendizagens. Entendemos que esse público específico, oriundo dos vários segmentos da sociedade, vem em busca da alfabetização e da escolarização, numa faixa etária que marca a identificação desse coletivo de alunos.

\footnotetext{
a Universidade do Estado da Bahia, Salvador, BA, Brasil.

b Universidade do Estado da Bahia, Salvador, BA, Brasil.

c Universidade do Estado da Bahia, Salvador, BA, Brasil.
} 
Durante a atividade docente, percebemos que existe uma preocupação com a mudança do perfil etário do público alvo atendido pela EJA. Neste sentido, Haddad (2015) já sinalizava para a mudança no perfil do aluno da EJA, que vem se configurando ao longo dos anos com a presença de alunos jovens. Assim, as escolas que oferecem essa modalidade de ensino procuram atender a alunos que retornam em busca da escolaridade na perspectiva de melhores condições de vida. Com isso, inicialmente, percebemos que a juvenilização representa um fenômeno resultante dos processos de insucesso escolar, o qual vem preocupando ao descaracterizar o formato originalmente proposto para a EJA.

Partindo desse enfoque, o estudo direcionou como temática a juvenilização da EJA e as implicações no processo de escolarização, evidenciando as nossas inquietações acerca de uma nova realidade presente na sala de aula, com a presença marcante de alunos cada vez mais jovens, à qual se soma a heterogeneidade de características individuais, sendo essa uma configuração da EJA. Nessa lógica, construímos o artigo - trabalho específico de disciplina acadêmica - levantando o seguinte problema: quais os principais motivos que levam os alunos jovens a buscarem cada vez mais cedo as salas de aula da EJA? O questionamento originou-se da percepção do crescente número de estudantes jovens nessa modalidade de ensino, requerendo a busca por informações que esclareçam um fenômeno que se multiplica sem qualquer cuidado e planejamento.

O objetivo geral foi o de investigar os motivos que determinam a inserção dos jovens na modalidade de ensino, as dificuldades vivenciadas no processo de escolarização e os impactos nas relações entre os alunos na sala de aula da EJA. Nessa perspectiva, o estudo possibilitou um melhor entendimento da nova especificidade que se apresenta na EJA, a importância do planejamento e de políticas educacionais, direcionadas à essa pluralidade humana rica em histórias de vida e de cultura.

Elegemos como objetivos específicos: conhecer as causas principais que levam os alunos migrarem para EJA; e investigar os impactos com a presença do aluno muito jovem na Educação de Jovens e Adultos. Nesse percurso investigativo, levamos em consideração os aspectos voltados às práticas pedagógicas que estão intrinsicamente ligadas ao contexto da escola.

\section{Procedimentos metodológicos empreendidos}

Nesse estudo investigativo, utilizamos a abordagem qualitativa de pesquisa, por entender que ela condensa uma gama de subjetividades, por se tratar de significados importantes que cada um dos atores sociais, tanto professores quanto alunos, 
apresentam ao discutirmos o tema e as revelações no percurso investigativo. Desse modo, as teorias que nortearam a metodologia do estudo, cunhadas no entendimento que a pesquisa qualitativa, responde a questões muito particulares, analisa um nível de realidade não quantificada, trabalha com um universo de significados observando os motivos, as aspirações, as crenças, os valores e as atitudes, tornando-se assim num espaço profundo das relações dos processos e dos fenômenos que estão sendo investigados (MINAYO, 2018).

Nesse sentido, a percepção da autora corrobora com o estudo por sinalizar o caráter exploratório no tocante às razões dos jovens alunos migrarem para a EJA. Outro elemento que se relacionou a este estudo foi o conceito de Minayo (2018), ao afirmar que não são os números que comprovam a realidade da pesquisa, mas os fenômenos individuais, quando categorizados, os quais podem apresentar o sentimento de uma coletividade com base nas crenças, nos valores, nas culturas e nas vivências que cada sujeito traz consigo. Acreditamos, pois, que, por meio dos resultados empíricos, conheceremos a realidade vivida nas escolas delimitadas.

O posicionamento de Ludke e de André, também chamou a nossa atenção ao explicitar que:

A pesquisa qualitativa então trabalha com o sentido de inteligência do pesquisador. Isso porque a preocupação com o processo é muito maior do que com o produto, pois é nessa fase que se constrói as hipóteses que nortearão a própria pesquisa e possibilitarão a formulação descritiva necessária para a construção de um novo conhecimento (2013, p. 21).

Tangente ao analisado pelas autoras, a nossa grande preocupação esteve voltada para os desdobramentos e para o dinamismo interno das situações que esperávamos encontrar e contextualizar junto às teorias que balizaram as nossas análises. Por assim dizer, a descrição dos dados e das informações que encontramos, na sua mais fiel tradução, foram de suma importância para alcançarmos o resultado final.

Para instrumentalizar a investigação, adotamos a pesquisa de campo, já que o seu desenvolvimento exige do pesquisador um encontro mais direto e a busca por um espaço onde acontece o fenômeno, mantendo uma postura democrática e liberal. Assim sendo, a pesquisa de campo se destacou pela importância do diálogo com o diferente, ou seja, com a nova realidade até então desconhecida, 
fazendo-se necessário um contato munido de criticidade, capaz de canalizar situações e novas vivências dos jovens, adultos e idosos, favorecendo o espaço de liberdade e de confiança com o pesquisado para possibilitar informações que traduzam a condição presente na escola.

Tratamos de um procedimento no qual o pesquisador foi ao encontro dos professores e dos alunos que aderiram à pesquisa, para a obtenção dos dados e das informações, observando o enfrentamento com tudo aquilo que fez parte da realidade estudada, a complexidade e a dinâmica do processo, na "Procura muito mais o aprofundamento das questões propostas do que a distribuição das características da população [...]” (GIL, 2019, p. 57).

Observamos que o autor enfatiza o entendimento da necessidade de um conhecimento prévio do caminho a ser percorrido na investigação, dos instrumentos a serem utilizados e das teorias que darão segurança ao pesquisador na coleta de informações de seu interesse para aprofundamento das questões analisadas. Assim sendo, todos os dados obtidos permitiram o estudo mais explicado da questão da juvenilização da EJA, detalhando os conhecimentos sobre o objeto da investigação, sendo possível chegar a uma conclusão, sem a pretensão de esgotar a discussão a respeito da temática.

O lócus da investigação foi constituído por escolas públicas estaduais e municipais, localizadas nos municípios de Barreiras e de Salvador, na Bahia. Escolas de grande porte e bem equipadas, aqui denominadas como Escola A, B, C, e D, sendo: a escola A, municipal da cidade de Barreiras, ofertando o Ensino Fundamental II e a EJA, nos turnos matutino, vespertino e noturno, atendendo a aproximadamente 1008 alunos, desses, apenas 168 na EJA nos estágios I e II; a escola B, estadual, na mesma cidade, ofertando o Ensino Médio e a Educação de Jovens e Adultos, atendendo a 416 (120 alunos da EJA); a escola C, também estadual, em Salvador, atendendo a um contingente de mil alunos, caracterizada como Centro de EJA, por abrigar alunos, fundamentalmente, da EJA, nos turnos diurno e noturno; e, por fim, a escola D, municipal, também em Salvador, ofertando o Ensino Fundamental e a EJA, atendendo a, aproximadamente, 800 alunos, desses, 223 matriculados na EJA.

Os sujeitos da pesquisa foram professores e alunos das escolas selecionadas que aderiram à pesquisa, compondo a amostra de investigação com: 27 professores, com idade que variou entre 25 a 55 anos de idade. Ainda, 37 alunos, de ambos os sexos, em sua maioria trabalhadores, sendo: 14 com idade variando entre 15 a 18 anos; oito alunos entre 19 a 22 anos; quatro alunos entre 23 a 25 anos; 
quatro alunos entre 26 a 30 anos; sete entre 31 e 40 anos. Todavia, a presença de alunos acima dos 29 anos, quando se configura o final da juventude, se deu pela necessidade de perceber os sentimentos e os impactos com a presença de jovens alunos com idade mais avançada.

O estudo foi apoiado na aplicação do questionário semiestruturado com inquisições fechadas e abertas para os professores das disciplinas das áreas de Exatas, Humanas e Línguas. Também a aplicação do questionário para os alunos da EJA: Tempo de Aprender I e II; Tempos Formativos I e II nos Eixos I, II, IV e V, seguindo o rigor científico apropriado para cada realidade, no intuito de aumentar a confiabilidade dos dados e as informações necessárias para substanciar a investigação com a análise dos dados, contribuindo para o aprofundamento dos resultados.

\section{A juvenilização da EJA: desafios atuais}

Os fundamentos sobre a juvenilização da EJA são necessários para entendermos as razões pelas quais os estudantes estão deixando de cursar o Ensino Fundamental - com os níveis de ensino e de faixas etárias estabelecidas - e passam a se inserir na EJA. Trata-se de um processo de anulação das políticas públicas e da falta de perspectiva para a Educação Básica, que, segundo Furtado (2015, p. 55): “[...] é resultado também desse processo de escolarização degradada, que perpetua a exclusão escolar. Os/as alunos/as têm acesso ao espaço físico, mas não, a uma educação de qualidade, que os/as considere como sujeitos de direitos".

Dessa forma, constatamos todo um processo de dificuldade na escolarização da Educação Básica brasileira, notadamente, a partir da segunda etapa do Ensino Fundamental até a conclusão do Ensino Médio, diante de um crescimento constante na matrícula de jovens adolescentes na EJA, gerando uma preocupação e um desafio para o sistema educacional atual.

Com isso, exigem-se que os gestores das escolas e dos sistemas de ensino repensem as ações de políticas públicas educacionais específicas na área, visando ao enfrentamento dos desafios interpostos no caminho da EJA e dos jovens estudantes. Para tanto, é preciso que professores e gestores fiquem atentos ao grau de exclusão dos alunos adolescentes - oriundos da escola com prática no ensino idade/série, escola de ensino seriado regular - que se aventuram na escola da EJA, sem participar das etapas necessárias para o seu caminho de escolarização, sendo mais evidente quando observamos as dificuldades educacionais presentes nas trajetórias de jovens das classes populares, que passam por uma degradação da cidadania, quando submetidos a um conjunto 
de pressão: social, ética e cultural; na luta pela existência e pela possibilidade de viver de forma digna em sociedade.

O alerta da presença de alunos muito jovens na EJA - que, por concepção, deveria ter como público alvo alunos trabalhadores, pessoas adultas ou idosas dos segmentos da sociedade civil - vem do insucesso escolar que retrata o problema vivido na escola regular e, também, as características que os identificam no processo de adolescência. Somam-se, ainda, os desafios sociais desses alunos, em particular a questão do acesso ao emprego e à renda, que, muitas vezes, seduz o aluno para o mundo do trabalho, promovendo a exclusão da vida escolar.

Por isso, não se pode esquecer a relação tensa e conflituosa vivida pelo jovem aluno da escola regular diante dos aspectos disciplinares e pedagógicos, fatores excludentes na perspectiva da interação social e cultural. Essas visões, atitudes e posturas acabam estigmatizando esse jovem aluno, rotulado como problema, o que não ocorre com o adulto, que busca de todas as formas avançar no processo de escolarização na EJA.

Consideramos que há um conjunto de desafios que vem sendo interposto no caminho da escola e do aluno juvenil na EJA. Nessa perspectiva, é preciso atentar para o fato de repensar a estrutura organizacional da escola com o objetivo de conta desse novo perfil de aluno que chega à EJA, com base no entendimento de que:

[...] o conhecimento do contexto se relaciona com o local em que se desenvolve o ensino e com as pessoas a quem ele é ministrado. Para cada turma, série e nível de ensino são feitas adaptações ao saber a ser construído. Esses saberes são adquiridos na prática, na vivência do cotidiano escolar. Os professores que atuam na EJA, se não tomarem consciência desses elementos na sua formação, ficarão reféns cada vez mais de práticas modeladores e de reproduções de práticas bem-sucedidas, que, na maioria das vezes, nada têm a dizer aos seus alunos (JARDELINO; ARAÚJO, 2014, p. 158).

A partir da compreensão dos autores, o proposto por lei para atender aos jovens e aos adultos trabalhadores vem sendo minado, perdendo o significado e a identidade original, com a presença do jovem aluno excluído da escola de ensino regular, o qual busca um refúgio na EJA - a via rápida para que possa superar os desencontros vividos na escola, ou mesmo uma solução para os seus problemas - como recurso possível e disponível à inclusão. Não seria absurdo dizer que 
eles vão à escola sem um propósito, uma expectativa ou um objetivo; estão nela apenas para dar sentido ao que preconiza a lei.

Não muito distante dos dias atuais, o processo de insucesso escolar gerou um contingente de alunos excluídos, em sua maioria, procedentes do campo, marcados fortemente pelo analfabetismo extremo e pela falta de oportunidades. Para o enfrentamento desse cenário, foi preciso estabelecer políticas públicas para atender o perfil desses sujeitos, com programas de alfabetização e escolarização. A partir daí a EJA assumiu o cunho social de inclusão, ao abrigar nos seus programas novos indivíduos que passaram pelo processo de exclusão, com histórico de abandono e de reprovação escolar.

Diante desse cenário, entendemos ser importante a configuração de novas práticas pedagógicas que atendam às proposições oriundas das transformações sofridas pela EJA, que vivencia o surgimento de um novo perfil de aluno - vindo em busca da escolarização, do resgate social quando preterido pela escola regular, que não lhe deu oportunidade de condições legítimas de direito, no tempo idade/série carente de acolhimento e de compreensão, excluído daquele espaço educativo.

Nessa lógica, pensar na concretização de metodologias e de práticas pedagógicas que assegurem a permanência de jovens e de adolescentes na escola regular, faz-se necessário para garantir a permanência, o desenvolvimento pedagógico e a formação cidadã. Da mesma forma, entendemos ser necessário repensar também as práticas pedagógicas na EJA após a migração de adolescentes e de jovens, que formam um grupo heterogêneo de sujeitos que se juntam aos adultos e aos idosos nas salas de aula da EJA, distanciados por idades, por experiências e por perspectivas de vida muito distintas e singulares.

Esse novo perfil de alunos muito jovens pressiona os indicadores da não permanência nas escolas da EJA e tem aguçado a nossa preocupação por estarem na convivência de pessoas com maior idade e mais experiência de vida, gerando uma necessidade latente de práticas pedagógicas que agreguem valores e contemplem a variação etária vivida na sala de aula. Por isso, acautelamos a necessidade de acompanhar os conflitos, promover a compreensão e o respeito aos saberes, valorizar a trajetória social, histórica e cultural de cada aluno, de forma a contribuir para que tanto o mais jovem quanto o mais adulto não percam o estímulo e desanimem diante das dificuldades e dos obstáculos encontrados nos processos de retorno à escola. Dessa forma, tanto educando como educadores serão responsáveis pelos processos educativos, tendo na atividade pedagógica um referencial, pois: 
[...] a educação é um ato inacabado haja vista que somos seres inconclusos e, constantemente, estamos ensinando e aprendendo ao mesmo tempo. Só ensina e aprende quem está aberto ao outro e, consequentemente, ao diálogo; e não por haver diálogo pautado na superioridade de um sobre o outro [...] (LOPES; AMORIM, 2018, p. 108).

Destarte, avalizamos o modelo de escola de EJA que contemple tamanha multiplicidade de caracteres individuais de sujeitos e multietariedade, que, na prática pedagógica humanizadora não assuma um caráter de infantilização, para atender ao grande número de adolescente que nela está, ou ao contrário.

Dotada do sentido humanizador, a EJA acolhe esses sujeitos que não tiveram acesso à escola no passado, ou dela foram colocados para fora, reconhecendo que esses têm uma vida rica em aprendizagens a ser valorizada. Sendo assim, mesmo com toda a variância de faixa etária e de histórico de vida, corroboramos a ideia da adoção de uma proposta de prática pedagógica que não venha a ser mais um motivo de conflito entre professor e aluno. Numa sala de aula heterogênea, como ocorre na EJA, o professor deve propor uma prática pedagógica que agregue todas as redes de saberes, tecida nos seus variados espaços/tempos e de experiências.

No modelo de sociedade meritocrática e individualista em que vivemos, destacamos a atenção da escola para com os sujeitos, no sentido da valorização de sua autoestima e do desenvolvimento de sua inteligência espacial, para buscar entender o lugar que ocupa, sem "culpabilização" e sem "vitimização". Assim, a linguagem e o tratamento dispensados para o aluno farão a diferença, desde que não desqualifiquem a sua formação, com a implantação de um tratamento infantilizado, que não venha a contribuir com o avanço do processo pedagógico e humanizador. Por isso, defendemos a atividade escolar não pensada de forma fragmentada, na qual professores e alunos tenham objetivos distintos na condução do processo de ensino-aprendizagem.

Nesse contexto, as práticas pedagógicas e de gestão escolar devem servir para o aperfeiçoamento e para a adequação do currículo, não distanciado dos objetivos da EJA, onde o grande número de jovem/adolescente que adentra o espaço escolar não venha representar um desafio para professores, gestores e, até mesmo, para o próprio aluno. Isso porque, diante da necessidade de conciliar e de dar conta dos objetivos, das necessidades e das expectativas, esses jovens se deparam com "[...] turma composta por sujeitos de diversas idades, vindos de realidades diversas, com diversas trajetórias escolares [...]” (SOUZA; REIS, 2017, p. 106). 
Torna-se, pois, um processo que requer inovação e reinvenção de escola, dada a extrema importância da EJA, com a utilização de procedimentos e de práticas que fortaleçam o seu verdadeiro papel no processo de transformação e de evolução enquanto modalidade de ensino, colocando-se como espaço de discussão, de enfrentamentos, de reflexões, de competências e de construção de novos saberes, coadunados aos já construídos, muitas vezes esquecidos, ignorados e invalidados, sendo necessário levar em conta a experiência e o conhecimento popular que o aluno leva até a escola (FERNANDES; GONÇALVES; AMORIM, 2016).

A diversidade que trazem esses novos atores sociais acena para o muito que ainda temos por discutir e por empreender, ao entender que o centro do desafio com a juvenilização na EJA é atender a diversidade marcada pela heterogeneidade das necessidades de aprendizagem, pelas motivações e pelas condições de estudo. "Destarte, uma outra relação entre conhecimento e vida se constitui por intermédios dos sujeitos em comunhão, freireanamente falando. Os espaços da Educação ganham outros sentidos, o sentido da vida, o sentido de vidas" (COSTA; EVANGELISTA, 2017, p. 62-63).

Estabelecemos, pois, novas formas de atendimento, que sejam diversificadas e flexíveis, para que a escola seja capaz de: acolher diferentes percursos e ritmos formativos, oferecer e consolidar propostas pedagógicas inovadoras com criteriosa seleção de conteúdos curriculares que estejam sintonizados com o mundo sociocultural, com a oferta de recursos didáticos e com linguagem apropriada para atender a pluralidade de faixas etárias.

\section{O enfrentamento dos desafios da juvenilização da EJA: visão de alunos e de professores}

Iniciamos essa etapa do estudo tendo em mente responder ao problema e aos objetivos que nortearam e instigaram a pesquisa sobre o processo de juvenilização da EJA, ao analisar a situação dos alunos nas quatro escolas investigadas. Buscamos apontar os motivos que levaram esses jovens recorrerem a essa modalidade de ensino, estando numa fase da vida e em uma faixa de idade que os condicionariam estar num contexto escolar que possibilitasse a sua vivência marcada pelas descobertas, pelas experimentações e pelas dúvidas.

Observamos o Quadro 1 no cruzamento dos dados resultantes da aplicação dos questionários: 
Quadro 1 - Situação social e econômica dos alunos da EJA nas escolas investigadas

\begin{tabular}{|lcc|}
\hline Atividades que exercem & Motivações principais & $\%$ \\
\hline Só estudam & $\begin{array}{c}\text { Tem a ajuda dos pais ou de outros parentes } \\
\text { para estudar }\end{array}$ & 40 \\
Trabalham em casa de família & $\begin{array}{c}\text { Vivem do salário que recebem no trabalho e } \\
\text { custeiam suas próprias despesas } \\
\text { Fivem de bico, não tem uma renda fixa }\end{array}$ & 10 \\
Tem trabalho fixo & $\begin{array}{c}\text { Tem atividade remunerada, trabalham o dia } \\
\text { todo e ainda vão para a escola } \\
\text { É jovem aprendiz }\end{array}$ & 24 \\
\hline & Vive a experiência oportunizada pelo mercado \\
de trabalho & 5 \\
\hline
\end{tabular}

Fonte: Elaborado pelos autores (2019).

Detectamos o percentual de $40 \%$ de alunos que estudavam e eram mantidos por pais ou parente; $24 \%$ que eram freelances e realizavam trabalhos considerados "bico", ou trabalhadores do comércio informal; $21 \%$ que eram trabalhadores registrados formalmente em empresas, o que significa serem alunos provedores do sustento das famílias; $10 \%$ eram trabalhadoras em casa de família, compondo o quadro de empregada doméstica; e 5\% eram de jovens aprendizes.

Portanto, o percentual de alunos que estudavam e eram mantidos por pais e/ou parente evidencia que a presença desses alunos na EJA não estava vinculada à questão do trabalho, pois nesse percentual incluia um número de alunos que estavam na faixa dos 15 aos 18 anos de idade. Sem grande rigor, podemos afirmar que houve uma semelhança de público ao nos concentrarmos no número de alunos que só estudam e identificarmos 2 alunas com idades acima dos 25 , sobre as quais deduzimos tratar de alunas que retornaram à escola.

O vínculo com o trabalho não ficou configurado junto aos alunos jovens. Tratou-se de alunos que migraram da escola de ensino regular para a EJA, motivados por questões pedagógicas, resultantes do insucesso escolar. Isto posto, avocamos a discussão das questões pedagógicas no contexto do Projeto Político Pedagógico, que faz da escola palco de conflitos entre o desejo do aluno e a prática pedagógica que está posta na escola.

Defendemos, pois, no cotidiano dessas escolas, a urgente necessidade de mudanças nas práticas educativas, no currículo e na forma de acolhimento, para que seja 
efetivado o processo de inclusão e de permanência do aluno jovem na escola. Nesse sentido, a responsabilidade da escola e a atuação do professor em sala de aula devem levar em conta fatores sociais, culturais, econômicos e a história de vida do aluno.

Assim, tanto os professores quanto os gestores atentavam para o papel que a escola tinha a desempenhar na vida dos alunos, considerada suas funções social e formativa. Nesse sentido, a condução do agir dos professores e dos gestores estava ancorada no amplo processo de conhecimento da realidade das instituições de ensino que instrumentalizam a EJA, em sintonia com as necessidades que os alunos trazem, visando entender e atingir um nível de conscientização para contemplar os sujeitos na perspectiva de fazer valer o desejo de estar na escola.

No que tange à busca dos jovens alunos pela EJA, esse entendimento pode sinalizar a necessidade da transgressão pedagógica, da inovação do ambiente pedagógico, da formação educacional do jovem para além da formação desejada, tornando-os pessoas conscientes, críticas e ativas numa sociedade que vem exigindo posturas capazes de sinalizar e de suprir as necessidades de aprendizagens e de conhecimentos associados às expectativas do mundo do trabalho.

Assim, as escolas devem reunir condições necessárias às propostas educativas que atendam às expectativas individuais e coletivas dos sujeitos, para solucionar os conflitos daqueles que buscam a EJA. Entretanto, não podemos esquecer a tríade: aprendizagem, experiência e currículo como a base da concepção político-pedagógica da escola voltada ao contexto dos alunos e aos objetivos de estarem no ambiente escolar.

As dificuldades vividas pelos alunos no processo de escolarização também foram influenciadas pelo mundo do trabalho. Assertiva baseada na análise dos dados, ao apontar que $60 \%$ dos alunos eram trabalhadores, isto somados os trabalhadores com carteira assinada, os freelances e as trabalhadores de casa de família. Os demais $40 \%$ não trabalhavam na época da investigação.

Os alunos trabalhadores reclamaram das dificuldades de chegar à escola, e mais: a dificuldade de cumprir o horário das aulas; o cansaço; o sono e a "falta de coragem" para ir à escola, sendo que as principais reclamações vieram dos alunos que trabalhavam como freelance, pois sempre tiveram jornadas de trabalho longas e em condições que levavam ao cansaço físico e, na sala de aula, 
eram vencidos pelo sono, fator que acarretava a falta de concentração e, em alguns casos, essa era a razão por abandonar da escola. São histórias repetidas ano após ano, que fazem perpetuar um histórico de negação de direitos, que têm suas causas no fator: social, cultural, político, econômico e, também, na própria escola.

O aluno que chega à EJA, enquanto acidentado do processo de escolarização, tem no trabalho uma das razões para o abandono, pois, "ou trabalha ou estuda", clichê muito presente no cotidiano e condicionante para assegurar o posto de trabalho que, ao se afastar da escola, ele só retorna quando surge uma nova oportunidade ou nova razão de para lá voltar. Os dados apontaram nesse sentido, pois, 50\% dos alunos afirmaram ter deixado de estudar por causa da jornada de trabalho e da dificuldade de chegar à escola, uma realidade presente na vida dos alunos trabalhadores, que tendo de cumprir horário no trabalho não conseguem chegar à escola no tempo previsto e, por essa razão, tendo prejuízos no percurso escolar, acabam por abandonar os estudos.

Entretanto, 31\% dos alunos afirmaram ter deixado de estudar por outros motivos, desde: falta de incentivo; as aulas não eram boas e os professores não inovavam; e, por fim, outros $19 \%$ afirmaram nunca ter deixado de estudar, sugerindo terem passado pelo processo da reprovação.

Observando esse perfil de alunos, a existência de dificuldades na escolarização foi impactada no movimento de ida à escola para alcançar avanços no processo de ensino/aprendizagem, por conta do desnível de conhecimento, do desenvolvimento cognitivo e dos objetivos individuais que influenciam as relações entre alunos e deles para com os professores. Foi com base nessas relações conflituosas que ouvimos a assertiva de um professor: "[...] os alunos não se comportam, eles não sabem conversar, são muito violentos" (P15).

O Gráfico 1 apresenta o posicionamento do coletivo de professores sobre as questões que envolvem a vida do aluno, observando o cenário em que vivem, especificamente ao conhecer os motivos que levaram a recorrer pela matrícula nas classes da EJA. Segundo os professores, são sujeitos de direitos, que vivem em busca de uma melhor alternativa para as suas vidas; pessoas das classes populares que tiveram o percurso educativo marcado por diferentes processos vividos na própria escola. Nesse sentido, os professores dividiram suas opiniões a respeito da razão pela qual os alunos retornam à escola na modalidade da EJA. 
Gráfico 1 - A manifestação dos professores sobre a razão dos alunos estudarem na EJA

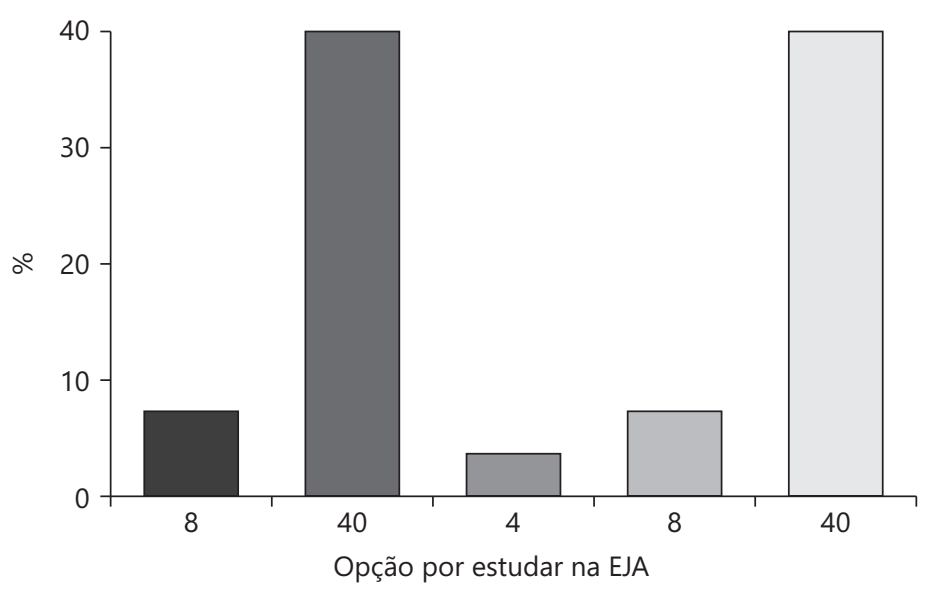
- O ensino da EJA desenvolve mais o aluno
$\square$ Concluir o ensino fundamental
口 Política da escola com aluno problema
$\square$ Necessidade de aprender a ler e escrever
$\square$ Questões relacionadas ao trabalho

Fonte: Elaborado pelos autores (2019).

Para $40 \%$ dos professores, as razões dos alunos recorrerem aos estudos na EJA advêm da necessidade de concluírem o Ensino Fundamental, sendo, muitas vezes, uma condição para acesso ao emprego. Outros $40 \%$ dos professores afirmaram que as razões são as questões relacionadas ao trabalho, sugerindo que o avanço nos estudos é uma exigência do mundo do trabalho. Outros $8 \%$ declararam que os alunos recorrem às salas de aula da EJA pela necessidade de serem alfabetizados. Na mesma proporção de $8 \%$, as razões foram creditadas à condição do aluno desenvolver-se mais na EJA. Por fim, 4\% dos professores afirmaram que a presença do aluno na EJA era uma política da escola com o aluno-problema e uma forma de puni-lo.

Os professores, em sua maioria, foram enfáticos ao defender que o retorno dos alunos ocorre porque o acesso à escola promove o desenvolvimento pessoal. Por essa razão, entendemos que as experiências de vida do aluno são determinantes para o desenvolvimento formalizado pela escola da EJA, que "[...] vem assumindo a função de restabelecer as trajetórias escolares desses sujeitos e deve, sim, imprimir foco na construção de projetos político-pedagógicos que os contemplem" (TEIXEIRA, 2018, p. 31). 
Por não coadunar com a política da escola com o "aluno-problema", que se utiliza da transferência para a EJA todo aquele aluno considerado à margem no campo disciplinar, a maioria dos professores sinalizaram contra essa prática por ter um significado negativo no processo contínuo que a escola utiliza para reprimir os alunos. Geralmente, aluno que vivenciou processos dicotômicos na escola e que chegou ao acirramento extremo, a ponto de a escola adotar política de tratamento diferenciado, transferindo-o para a EJA na condição de "aluno- problema".

Entendemos que uma escola que valoriza o castigo não é uma escola inteligente; ela vive sob os auspícios de valores ortodoxos e ultrapassados, despreza os valores éticos e morais que determinam o bom viver e afasta esses sujeitos do bem maior, que é o esperançar da vida. Para Arroyo (2017, p. 92), "[...] toda dicotomia é cômoda e simplória. Quando essa dicotomia reage ao olhar docente é anti-educativa. As vidas dos alunos são complexas demais para caberem em classificações dicotômicas, simplórias".

Os alunos que viveram processos socioeconômicos que os discriminam e os distanciam dentro e fora da escola, têm na condição de vida as bases históricas e sociais que os conduzem ao entendimento do papel que a escola exerce em sua vida e ao longo de sua caminhada. Foi o que mostrou a declaração de dois alunos: "Não gostava das aulas, achava tudo muito chato, só gostava da escola por causa dos colegas" (A6) e "As aulas não eram boas e os professores não inovavam" (A10).

A compreensão do significado "não gostar", verbalizado pelo aluno A6, e "não eram boas" e "não inovavam" manifestado pelo aluno A10, perpassa pelo arcabouço da escola não criativa e que não desperta o interesse do aluno. Desperta para um olhar que precisa ser ressignificado pelo conjunto dos atores que fazem a escola, pois é preciso " [...] conhecer os sujeitos da EJA, suas trajetórias, identificando seu perfil, suas expectativas e vivências, para que eles possam ser considerados na construção de propostas e projetos que venham atender-lhes de maneira mais próxima e específica" (JARDELINO; ARAÚJO, 2014, p. 171).

Assim, aqueles que fazem a escola precisam entender a necessidade de sair dessa inércia que se instalou sobre as instituições educativas, configurando um atraso pedagógico, tecnológico e cultural. Devem estar atentos para as mudanças institucionais, com vista à promoção de uma nova consciência reflexiva, que tenha uma base epistemológica no papel social, educacional e político que tem a escola atual. Essa visão é retratada no posicionamento do aluno A32: 


\begin{abstract}
A escola é uma preparação para nós podemos arrumar um emprego bom e ter uma vida melhor lá no futuro. Ter uma boa vida, bom serviço, uma boa casa e um bom carro. A tecnologia hoje em dia nos ajuda muito com computadores, na escola e no saber de informática e tecnologias. Ajudam no desenvolvimento de nós alunos e então o estudo vai nos ajudar bastante na frente com bom serviço e uma boa casa e um bom carro.
\end{abstract}

Na narrativa ficou claro o sentido que ele e a maioria dos alunos têm da escola, tratando-se de um marco educacional que pode alavancar a vida social e econômica desses sujeitos, daqueles que clamam pela construção de novos caminhos para trilhar a vida, tendo na presença da escola a instituição da sociedade que promove a consolidação de conceitos inovadores e desperta em todos a busca por uma consciência da vida, que ajuda a enfrentar os desafios do mundo atual. Esta consciência também foi manifestada por uma aluna, valorizando o papel da escola, ao afirmar que:

A escola é muito importante para minha vida, pois sem os estudos não podemos conquistar nada na vida. Apesar dos tempos perdidos que eu perdi, estou na minha escola buscando recuperar o tempo perdido para obter novas vitórias e conquistas que a minha escola me propõe (A13).

Nessa perspectiva, os professores valorizavam e incentivavam os alunos a buscarem a conclusão dos estudos que realizavam e foi apontada pelos professores P5, P17 e P20, ao afirmarem sobre a EJA:

Garantida pela Constituição como um direito do aluno, a EJA deve proporcionar a qualidade do processo de ensino e aprendizagem; desse modo, o curso deve ser pensado e planejado de forma a possibilitar o acesso e a permanência do aluno, o que implica necessariamente o desenvolvimento de práticas pedagógicas que valorizem suas experiências e seus conhecimentos prévios e considerem o vínculo entre educação, trabalho e práticas sociais e culturais.

Para o professor P18, “[...] o processo formativo deve estar vinculado ao ensino-aprendizagem, para que os alunos alcancem os objetivos que tanto anseiam". Vivemos num mundo de disputas acirradas pelo processo de acesso ao emprego, onde as competências e as habilidades tomam conotações de paridade e de potencialidade para esses indivíduos, sendo que, muitas vezes, 
eles estão desprovidos da escolarização. Dessa forma, apostam na escola para o reencontro com a Educação formal, na perspectiva da certificação, que possibilita a oportunidade de manutenção ou de conquista do posto de trabalho.

Infelizmente, em alguns casos, a realização humana desses jovens assume um sentido pouco convencional, foge ao conceito do "socialmente correto", com o abandono do projeto de vida. O abandono da escola em prol da manutenção ou alternativa de trabalho vem da necessidade de os jovens buscarem formas de ajudar financeiramente suas famílias e, no caso dos alunos mais velhos, vem da dificuldade de conciliar trabalho e estudo, impactando na vida desses sujeitos.

A presença dos alunos mais experientes convivendo com o jovem/adolescente reverbera na turma da EJA, pois o convívio tem sido marcado por conflitos, uma vez que, para os professores e para os alunos com idade mais avançada, a presença do jovem na escola representa uma ameaça à ordem da escola, marca imputada a esses jovens que chegam desanimados e desmotivados, modificando o cotidiano e as relações entre os sujeitos que ocupam o espaço escolar.

Laffin (2013) alerta que é preciso atenção dos professores na observância da realidade dos alunos durante a elaboração do planejamento das atividades e atuação na escola, aproximando a escolarização da realidade do mundo do trabalho, do emprego e da renda, certos de que o aluno da EJA, em sua maioria, exerce uma atividade laboral. Nessa direção, os dados apontam que $62 \%$ dos alunos pesquisados eram trabalhadores e $38 \%$ não trabalhavam, apesar de nessa categoria estarem inseridos os jovens aprendizes.

Portanto, o mundo do trabalho apresenta-se como uma mola das variações que essa modalidade de ensino vem assumindo, sendo coerente com a concepção inicial de escola como perspectiva de vida para todos. Assim, chegamos à enfática realidade da EJA e do processo de juvenilização dessa modalidade de ensino, demonstrando que tal processo não está distanciado das questões sociais, econômicas, políticas e educacionais de nosso tempo.

\section{Considerações finais}

Discutir a temática foi desafiador diante da relevância e da importância do tema e pela necessidade de contextualizar o fenômeno da juvenilização, que ameaça a caracterização da EJA com a presença do jovem aluno determinando o conflito intergeracional que afeta as relações na sala de aula e preocupa os professores e os gestores das escolas. 
Marcou o posicionamento do jovem aluno da EJA entender que a escola tem muito a ver com o seu objetivo de vida, que para ele a escola é uma das principais opções para direcionar sua trajetória de vida porque traz a Educação, que é fundamental para a humanização das pessoas, sendo um espaço que precisa ser melhorado e ampliado para alcançar as conquistas sociais dos alunos. Os professores defenderam uma escola voltada para a diversidade da população de alunos jovens e adultos, que requer o bom acolhimento e o compromisso político e educacional para atender a busca desses alunos. Foi manifestado por alunos e professores que a escola ainda não está preparada para enfrentar os desafios apresentados no processo de escolarização com a presença juvenil de alunos e a formação de um novo perfil de sujeitos da EJA.

A questão da busca pelo trabalho, pelo emprego e pela renda, bem evidenciada na vida dos sujeitos, não é a única razão que leva à presença do aluno muito jovem e à promoção do desequilíbrio nas relações entre os alunos na sala de aula da EJA. A questão pedagógica permeia e aparece como sendo uma das causas das divergências na sala de aula, cuja origem é o ensino regular, que, com a exclusão escolar, faz o jovem aluno desembocar na EJA como alternativa de inclusão repercutida com a presença de alunos mais jovens, que, originariamente, não era o público alvo dessa modalidade de ensino.

Entendemos a necessidade de atender a esse novo público, sem ferir o conceito inicial da EJA, que é o de abarcar todos aqueles que não tiveram oportunidade de concluir a formação escolar na "idade certa", em função das realidades sociais, econômicas, políticas e educacionais a que foram submetidos. Por assim dizer, acreditamos que a "juvenilização na EJA", no contexto da realidade educacional, requer a conscientização de todos partícipes da conjuntura escolar no repensar: do planejamento escolar e das práticas pedagógicas, que tanto expulsam os alunos da escola, quer seja do regular ou da EJA; das ações geradas pelas políticas públicas; da visão social da escola e suas práticas educativas que atendam às necessidades e expectativas do seu público, em particular o juvenil, sob pena de gerar um novo passivo social vindo do mundo da Educação de Jovens e Adultos. 


\title{
Juvenilization of Adult and Youth Education and the implications for the process of schooling
}

\begin{abstract}
The research analyzes the juvenilization in the Young and Adults Education, highlighting the causes of this process and implications in schooling. It aims to reflect on the reasons that determined the insertion of young people in the Young and Adults Education, specifying the causes and the impacts lived. The research approach is qualitative, anchored, strategically, in the field research. The data search was accomplished using a semi-structured questionnaire, which was applied to the research subjects: 27 teachers and 37 students from the public schools of Barreiras and Salvador, Bahia. The results showed to the influence of students 'work on the schooling process; the struggle to ensure access/stay at school; pedagogical practice; and school management as tool for promoting inclusion with dialogue, Teaching quality and equity.
\end{abstract}

Keywords: Young and Adults Education. Juvenilization. Quality Teaching. Schooling.

\section{Juvenilización de EJA y las implicaciones para el proceso de escolarización}

\section{Resumen}

El estudio analiza la juventud en la Educación de Jóvenes y Adultos (EJA), destacando las causas de este proceso y las implicaciones para la escolarización. Tiene como objetivo reflexionar sobre las razones que determinaron la inclusión de los jóvenes en EJA, precisando las causas e impactos experimentados. El enfoque de investigación es cualitativo, estratégicamente anclado en la investigación de campo. La recolección de datos se logró mediante el uso del cuestionario semiestructurado, aplicado a los sujetos de la investigación: 27 docentes y 37 estudiantes de escuelas públicas de Barreiras y de Salvador, en Bahía. Los resultados señalaron la interferencia de la actividad laboral de los estudiantes en el proceso de escolarización; la lucha por garantizar el acceso/permanencia en la escuela; la práctica pedagógica y la gestión escolar como impulsoras de la inclusión con diálogo, calidad docente y equidad.

Palabras clave: EJA. Juvenilización. Educación de Calidad. Escolarización. 


\section{Referências}

ARROYO, M. F. Imagens quebradas: trajetórias e tempos de alunos e mestres. Petrópolis: Vozes, 2017.

COSTA, A. A. F.; EVANGELISTA, F. Reflexões sobre ser jovem na Educação de Jovens e Adultos no Brasil. Crítica Educativa, Sorocaba, v. 3, n. 3, p. 56-65, ago./dez. 2017. https://doi.org/10.22476/revcted.v3i3.285

FERNANDES, G. P.; GONÇALVES, P.; AMORIM, A. Gestão de recursos tecnológicos em colégios estaduais baianos: as múltiplas possibilidades de ação pedagógica na EJA. Ensaio: Avaliação e Politicas Públicas em Educação, Rio de Janeiro, v.24, n. 93, p. 890-909, out./dez. 2016. https://doi.org/10.1590/S0104-40362016000400006

FURTADO, Q. V. F. Jovens na educação de jovens e adultos: produção do fracasso no processo de escolarização. João Pessoa: Editora Universitária/UFPB, 2015.

GIL, A. C. Métodos e técnicas de pesquisa social. 6. ed. São Paulo: Atlas, 2019.

HADDAD, S. Sistematização de práticas não escolares e ações coletivas: o sentido da educação popular hoje. In: REUNIÃO NACIONAL DA ANPED, 37., 2015, Florianópolis. Anais[...] Rio de Janeiro: ANPED, 2015. p. 1-23.

JARDELINO, J. R. L.; ARAÚJO, R. M. B. Educação de jovens e adultos: sujeitos, saberes e práticas. São Paulo: Cortez, 2014.

LAFFIN, M. H. L. A constituição da docência entre professores de escolarização inicial de jovens e adultos. Ijuí: Ed. Unijuí, 2013.

LOPES, E. J.; AMORIM, R. M. (orgs.). Paulo Freire: culturas, ética e subjetividades no ensinar e aprender. João Pessoa: Editora do CCTA, 2018.

LUDKE, M.; ANDRE, M. E.D.A. A pesquisa em educação: abordagens qualitativas. 2. ed. Rio de Janeiro: E.P.U., 2013.

MINAYO, M. C. S. (org.). Pesquisa social: teoria, método e criatividade. Petrópolis: Vozes, 2018.

SOUZA, E. O.; REIS, R. Juventudes na educação de jovens e adultos: contradições entre suas conquistas como sujeitos de direitos e os silenciamentos nos espaços escolares. Holos, v. 33, n. 3, p. 98-109, 2017. https://doi.org/10.15628/holos.2017.5747 
TEIXEIRA, E. O. A "fabricação" do jovem da EJA: reflexões sobre juvenilização e diversidade étnico-racial. Educação em Debate, Fortaleza, v. 40, n. 75, p. 25-36, jan./abr. 2018. https://doi.org/10.24882/eemd.v40i75.550

\section{Informações sobre os autores}

Alcides Alves de Souza Filho: Mestre em Educação de Jovens e Adultos. Professor da Rede Estadual de Educação do Estado da Bahia. Contato: alcisofilho@hotmail.com (iD) http://orcid.org/0000-0002-7252-3164

Atenuza Pires Cassol: Mestra em Educação de Jovens e Adultos. Professora da Rede Municipal de Educação de Barreiras, Bahia. Contato: atenuza@hotmail.com (iD) http://orcid.org/0000-0003-3382-2900

Antonio Amorim: Pós-Doutorado em Difusão do Conhecimento pela Universidade Federal da Bahia. Doutor em Psicologia pela Universidade de Barcelona. Professor Titular Pleno do Programa de Educação de Jovens e Adultos da Universidade do Estado da Bahia. Contato: antonioamorim52@gmail.com

(iD) http://orcid.org/0000-0003-3236-9139 